\title{
A criatividade em jogo: paráfrase e polissemia no processo de produção do discurso publicitário ${ }^{1}$
}

\author{
Fábio Hansen²
}




\section{Resumo}

Este artigo apresenta como objeto de investigação o processo criativo publicitário na perspectiva teórica da linguagem a partir da Análise de Discurso. Em nossa abordagem examinamos o funcionamento polissêmico e parafrástico do processo de constituição do discurso publicitário. O objetivo é analisar de que modo afloram nele a criatividade e a produtividade. Para cumprir tal objetivo, recortamos sequências discursivas produzidas a partir da observação de um processo criativo em uma agência de propaganda, e por meio de entrevistas com profissionais de criação que dele participaram. Assim, atestamos que o processo de criação publicitária é repleto de paráfrases. Logo, é um lugar de produtividade. Os criativos trabalham sob o efeito de liberdade criativa, produzindo um efeito de criatividade na concepção do dizer publicitário.

\section{Palavras-chave}

Criação publicitária, discurso publicitário, paráfrase, polissemia, brainstorm.

\section{Abstract}

The object of this study is the investigation of the advertising creative process from a Discourse Analysis theoretical perspective, concerning the polysemic and paraphrastic functioning of the advertising discourse constitution process. The objective is to analyze how creativity and productivity are generated. In order to do that, we separated excerpts of discourse sequences produced from the observation of a creative process in an advertising agency and the interviews of creation professionals who participated in the aforementioned process. Thus, we attest that the advertising process is riddled with paraphrases. Therefore, it is a productivity place. The creative personnel work under the creative freedom effect, producing a creativity effect in the advertising speech.

\section{Keywords}

Advertising design, advertising speeches, paraphrase, polysemy, brainstorm. 


\section{Introdução}

A economia criativa (PINHEIRO; MARTINS; BARTH, 2014) se configura em um dos mais dinâmicos conjuntos produtivos do mundo, incluindo atividades em que a força criativa se constitui no elemento central da produção de valor, como os setores culturais e de entretenimento, o design, a moda e, claro, a publicidade, que tem na criação a sua essência. A despeito disso, a maioria dos estudos sobre publicidade recai "sobre o produto final, seja um anúncio, um comercial entre outras peças" (ALVES, 2012, p. 2), e raros se voltam para os modos de "fazer da publicidade por meio da observação de métodos de trabalho" (Ibid., p. 2). "Há poucas contribuições acadêmicas sobre o assunto e uma pequena bibliografia que se restringe a abordar brevemente o processo de produção de ideias no caso específico dos publicitários" (CARRASCOZA, 2008, p. 17).

Neste texto propomos tratar a criatividade do campo publicitário exatamente pelo seu contrário, jogando com as noções de paráfrase e polissemia recolhidas da Análise de Discurso (doravante AD) conforme um desdobramento feito por Orlandi à abordagem de Pêcheux. É em função da distinção na $A D$ entre criatividade e produtividade que a questão central se impõe. Para Orlandi (2001), a produtividade produz a variedade do mesmo. A criatividade, por sua vez, implica a ruptura, o deslocamento das regras. Faz intervir o diferente. Então indagamos: o que encontramos com mais frequência na construção do discurso publicitário? O processo de constituição do discurso publicitário é criativo ou produtivo?

Para a compreensão do processo de elaboração do discurso publicitário, observamos o fluxo de trabalho de profissionais de criação, pois, como desafia Carrascoza (2008, p. 136), "somente mergulhando ainda mais no universo da criação publicitária poderemos descobrir o que há nas profundezas de seu discursorio". Diante disso, a reflexão sobre o ofício publicitário é uma contribuição para que se compreenda o funcionamento discursivo da produção de ideias em suas instâncias, enxergando criticamente o campo da comunicação e da linguagem. 
Relativamente à materialidade discursiva para fins de análise, tomamos as produções discursivas de profissionais de criação - participantes de um processo criativo em uma agência ${ }^{3}$ de propaganda da cidade de Porto Alegre/RS - como corpus, de onde recortamos sequências discursivas (SDs) obtidas em entrevistas em profundidade 4 com o redator e o diretor de arte, mas, sobretudo, por meio do acompanhamento do processo criativo, em especial do brainstorm ${ }^{5}$, pois o processo de criação teve nele o seu auge. Ao centrar esforços no brainstorm, estudamos essa que é uma das técnicas de criatividade mais exploradas no fazer publicitário. As sequências discursivas oriundas das entrevistas e da observação durante o brainstorm foram originadas com base nas transcrições do material coletado em áudio, e são, portanto, orais. Em suma, o intento foi examinar o processo criativo por meio dos diálogos internos da criação.

\section{A criatividade no campo publicitário: paráfrase e polissemia}

A fim de esclarecer a distinção entre criatividade e produtividade, recorremos a autores que representam o campo da comunicação e da criatividade. Martins (1997, p. 68) define a criatividade como "a capacidade de dar existência a algo novo, único e original". Já para Predebon (1997), a criatividade pode ser vista tanto como capacidade de produzir coisas novas e valiosas quanto uma técnica para equacionamento de problemas.

No discurso publicitário, para o dizer ser uma forma do novo, desloca-se o velho. Os textos, ao se fingirem de novos, soam, para os que já os haviam dito, 
como velhos. Barreto (1997) sugere que o publicitário precisa ter claro que as respostas antigas podem ser úteis, mas isso não impede que novas respostas também possam ter uma solução para um problema. "A comunicação publicitária se apropria de experiências comuns, coletivas, na tentativa de direcioná-las e preparar um território favorável para o contato com o produto. Este, quando ocorrer, não será uma experiência original" (BURROWES, 2005, p. 12).

Pela perspectiva da $A D$ não há dizer sem história, pois todo discurso é parte de um processo discursivo mais amplo que o toma em sua rede de significações. Contudo, a propaganda joga com a projeção de novidade, sendo uma das manifestações da apologia à criatividade, do "dever" criativo que persegue obsessivamente o publicitário. É no mínimo estranha essa criatividade que mantém o sujeito em um retorno constante a um mesmo espaço dizível. O que o publicitário, na função-autor, pelo menos tenta fazer é organizar as vozes de uma maneira original, configurando a criatividade como uma instância do processo de produção de sentido. Diante disso, indagamos: é sustentável a compulsão dos publicitários pela originalidade e a obsessão pela criatividade? $\mathrm{Na}$ constituição do discurso publicitário aflora a criatividade ou a produtividade, ou, pelo viés da $A D$, a polissemia ou a paráfrase?

Há necessidade de distinguir criatividade e produtividade, e de situar a relação entre o processo parafrástico e o polissêmico, isto é, considerar a relação entre a variedade do mesmo e o diferente. Nesse sentido, Orlandi (1987) define a criação, em sua dimensão técnica, como a reiteração de processos já cristalizados. Dieguez (2006), mesmo não sendo do campo da $A D$, pensa de maneira similar a Orlandi ao tratar dos mecanismos de reprodução de um repertório cristalizado. Além disso, crê que o discurso publicitário atua sobre uma novidade sedutora, contudo temporária.

Enquanto a paráfrase é a "matriz" do sentido, a polissemia é a "fonte" do sentido, uma vez que ela é a própria condição de existência dos discursos. Se os sentidos não fossem múltiplos, não pudessem ser outros, não haveria necessidade do dizer. A polissemia é justamente a simultaneidade de movimentos distintos 
de sentido no mesmo objeto simbólico. A articulação entre os dois processos é o jogo entre o mesmo e o diferente na linguagem, mas é difícil traçar limites estritos entre eles (ORLANDI, 1987).

A paráfrase abarca formulações diferentes que tendem para o mesmo sentido - o diferente no interior do mesmo -, retornando a um mesmo espaço dizível. A paráfrase é um novo enunciado, utilizando outros recursos linguísticos que mantêm o pensamento do original. Pode-se nomear esse processo de produtividade, em virtude da reprodução dentro do mesmo, da reiteração do efeito de sentido.

\section{A paráfrase em ação}

Para a constituição de um trabalho analítico, inserimos as sequências discursivas (SDs). Na SD1 (a seguir) fica explícito que a determinação do sentido é impetrada pelo anunciante. É ele quem define o que será dito. Cabe à dupla de criação "arranjar a maneira mais interessante disso chegar nas pessoas" (SD2). Dito de outro modo, no processo criativo os publicitários precisam encontrar formulações diversas - a variedade (como dizer) - que indiquem o mesmo efeito de sentido - o mesmo (o que dizer).

SD1 - a mensagem do que o cliente quer passar tem que vir do próprio cliente.

Nesse aspecto, as SDs 2 e 3 são complementares. Ambas reafirmam que a dupla de criação necessita parafrasear o que o anunciante gostaria que fosse dito ao seu público e, para isso, há diferentes modos de dizer, materializados nas ideias criativas durante o brainstorm.

SD3 - primeiro leio o briefing, procuro entender bem o que deve ser dito. Eu leio o briefing e eu procuro uma resposta. Tipo o que eu tenho que falar pro consumidor. Em cima disso eu começo a pensar em formas interessantes de se falar isso.

Nas SDs 4 e 5 esclarecemos o que o anunciante queria dizer, qual o efeito de sentido que gostaria de produzir. 
SD4 - expandir, atravessar fronteiras, ultrapassar, aumentar, chegar.

SD5 - falar em crescimento, já que resultados mostram que o cliente está expandindo.

Entre as ideias dos profissionais de criação, selecionamos algumas (SDs 6,7 e 8) que elucidam as várias formas de dizer.

SD6 - fase de crescimento com tênis menor e dedo para fora furado.

SD7 - conforme vai escrevendo a fonte vai crescendo. Há espaço para crescer. Está crescendo tanto que teve que ir para outro estado também.

SD8 - o texto estourado, encostado nas bordas ou até cortando um pouco as letras, para dizer que o cliente está expandindo.

As SDs 6, 7 e 8 revelam as distintas maneiras dos criativos, no brainstorm, em dizer que o anunciante estava crescendo, isto é, em parafrasear o briefing. No nosso modo de ver, o anúncio é uma paráfrase do briefing (essa é a face do "mesmo" que também produz a alteridade), do qual o brainstorm é parte constitutiva; os publicitários são responsáveis por essa paráfrase. Assim como é traduzido para os criativos, via briefing, o que o anunciante quer dizer é traduzido pelos criativos para o público, pois aquele sabe o que quer, porém não sabe conceber a materialidade discursiva. Por conseguinte, o processo de criação é repleto de paráfrases, na medida em que o briefing é uma espécie de molde a ser seguido no desenvolvimento das peças publicitárias.

Se para Orlandi (1987) a paráfrase não representa criatividade, reiteramos que o processo criativo do discurso publicitário é um processo de produtividade, em razão do "controle" de reprodução do mesmo efeito de sentido em todos os momentos ${ }^{6}$ do percurso e entre todos os sujeitos envolvidos, desde o anunciante, 
passando pelos publicitários - atendimento, planejamento, dupla de criação, diretor de criação - até chegar ao público, no qual finalmente se desencadeia o processo polissêmico. Dependente da polissemia, a criatividade se efetiva no contato do anúncio com o seu leitor e no efeito provocado pelo primeiro neste, quando então os sentidos escorregam.

Considerando que o consumo do anúncio é parte do processo de circulação, não nos cabe examiná-lo em pormenor. Todavia, vale acrescentar que a criatividade é atribuída pelo público leitor, em um estágio mais amplo do processo publicitário. Por meio do seu processo de leitura, ele é quem legitima o criativo como tal, isto é, em um movimento de reconhecimento da criatividade; apenas a atribui ao publicitário, dependendo do seu imaginário sobre criatividade.

Nessa dualidade, paráfrase e polissemia vivem em constante tensão. A paráfrase, ao retornar sempre ao mesmo espaço do dizer, causa a sensação de reprodução. Já a polissemia possibilita a multiplicidade de sentidos, o deslocamento do mesmo e o indicativo da ruptura em função da produção de sentidos diferentes, não perpetuando a noção de sentido literal (que, aliás, também é efeito). É a polissemia que desloca o sentido e o aponta para a criatividade, fazendo intervir o diferente. Ela é o indicativo da ruptura no processo de criação em função da produção de sentidos diferentes daqueles determinados no briefing.

Por isso, o profissional de criação também vive em constante tensão. $\mathrm{Na}$ tentativa de se legitimar na condição de criativo, deseja romper com normas preestabelecidas, para provocar estranhamento. Nessa hora, o conflito do sujeito criativo se acentua. Ele se divide entre o desejo de seguir livremente as ideias que lhe agradam - instaurar-se-ia, desse modo, a noção de ruptura com um deslocamento das regras, que se estabelece com a presença do diferente, da novidade; tudo isso faz parte de uma lógica da ruptura - e a frustração com a falta de criatividade das ideias, decorrentes, sobretudo, da necessidade de encaixá-las nos moldes do que foi solicitado pelo anunciante. 
À medida que detectamos a criação do discurso publicitário como reprodução de sentido, sendo da ordem da produtividade, compreendemos mais facilmente que o que se produz é o efeito de criatividade. Esse efeito consiste em (re)adaptar o que é antigo, o que já foi experimentado em outras ordens discursivas, por outros sujeitos. A criatividade não é uma atividade livre do sujeito, pois a apropriação dos pré-construídos é determinada pela formação discursiva que o determina. Significa estabelecer que se o dizer tem história, na prática do processo criativo há sempre um novo sentido atribuído. Logo, as ideias não são originais, embora possam parecer provenientes de uma voz anônima. Quebra-se a concepção de originalidade e se estabelece outro efeito (de originalidade), decorrente da ilusão da origem e da realidade do pensamento do sujeito, atribuída aos esquecimentos ${ }^{7}$ número um e número dois, e os apagamentos que eles invocam.

O apagamento do processo de produção de ideias aos olhos do grande público serve para camuflar o discurso-outro do discurso publicitário e mascarar intensamente a sua heterogeneidade constitutiva. Por extensão, tal "apagamento" provoca no criativo a ilusão de liberdade e de origem do dizer, além da fantasia do controle dos sentidos que o leitor real atribui à peça publicitária. Esse procedimento mantém a ilusão de que ele, o publicitário, foi quem pensou em todos os novos sentidos que o anúncio pode produzir, legitimando não só sua criatividade, mas também sua profissão, reforçando o estereótipo de que a publicidade é fruto de insights e lampejos criativos, alimentando o rótulo de que os publicitários são gênios, dotados de dons, e que as suas ideias nascem em um momento de iluminação quando bem entendem, porque no imaginário social a única coisa que os faz publicitários é a ideia diferente, que está arraigada no seu DNA.

7 Mecanismo de esquecimento número um: permite, de acordo com Pêcheux (1993), a ilusão de o sujeito ser fonte do seu discurso. Possibilita que a interpelação aconteça sem o conhecimento do sujeito. Mecanismo de esquecimento número dois: provoca no sujeito a ilusão da realidade do seu pensamento, de acordo com Pêcheux (1993). O sujeito tem a ilusão de que os seus dizeres são livres e seus, mas ele só fala aquilo que Ihe é permitido pela formação discursiva em que está inscrito. 
A demonstração de que os criativos se iludem ao se imaginarem a fonte do seu discurso, e ao considerarem possível controlar os sentidos junto ao leitor está na SD9. Ela não deixa dúvidas sobre a subordinação ideológica ao dizer do anunciante. Ao mesmo tempo reitera, ao atender uma solicitação do anunciante, a tentativa de controlar os sentidos produzidos pelo seu dizer, isto é, a condição de reprodução do processo de criação.

SD9 - a gente pegou um pássaro que estava voando, só que ele estava aterrissando e o cliente pediu que ele tivesse indo para cima e não para baixo, para não dar nenhuma sensação de 'estamos caindo'.

Nessa mesma SD9 vislumbramos novamente a paráfrase no processo de elaboração do discurso publicitário. Na ideia criativa reprovada porque o pássaro estaria supostamente "caindo", o anunciante ocupou o lugar do leitor imaginário, antecipando uma reação e supondo, assim como os publicitários, controlar os sentidos, uma vez que o leitor real pode gerar a polissemia mediante o contato com a materialidade discursiva. A interpretação poderia ser a mesma antecipada pelo anunciante (de queda) ou, pelo contrário, ser completamente inesperada e em direção oposta ("chegamos ao nosso destino"). Isso confirma que os publicitários perdem o controle sobre seu dizer quando este passa a circular livremente.

Mesmo que o anunciante hipoteticamente dissesse ao seu público que sua empresa está em decadência para produzir o sentido de que está em queda livre, o processo de criação continuaria caracterizado pela paráfrase. O pássaro aterrissando seria apenas uma ideia dentre diferentes formulações para produzir um mesmo efeito de sentido (cair, descer). Seja como for, não haveria segurança quanto à manutenção dos sentidos por parte do leitor, pois é o gesto interpretativo que gera esses efeitos de sentido. O pássaro em posição de descida tanto pode significar negativamente (decrescer) quanto positivamente (chegar, aterrissar, encontrar um ponto de apoio, marcar território). São sentidos derivados de interpretação. Por conseguinte, sobre a paráfrase (no processo de produção de 
ideias) o anunciante e os publicitários têm domínio, haja vista que ela ocorre no espaço de manobras da enunciação, no qual o dizer pode ser reformulado pelo sujeito. O criativo ocupa um lugar de paráfrases em um processo controlado de derivações, levando em conta que as derivações possíveis se dão em um espaço de (re)negociações. Já em relação ao efeito de sentido provocado, os criativos não têm controle sobre o uso de suas narrativas, porque a interpretação não é mais da responsabilidade do sujeito produtor do discurso.

A SD9 reaviva a preocupação no processo de criação em retornar a um mesmo espaço dizível, fazendo com que a paráfrase esteja presente em todos os momentos do percurso criativo. Novamente evidenciamos o processo constitutivo do discurso publicitário como não sendo da ordem da criatividade. O processo é reprodutor e não criativo, por mais contraditório que possa parecer definir um processo dito criativo como não criativo. Em palavras mais brandas, o processo de criação do discurso publicitário consiste, de fato, em um processo produtivo. Dessa maneira, o que se destaca é o produto final, o anúncio. Os momentos do processo são apagados por meio dos esquecimentos número um e número dois de Pêcheux (1993).

Como a matriz do sentido está na paráfrase, vale dizer, estará no processo de produção dos publicitários. Já a fonte do sentido está na polissemia, ou seja, no encontro entre anúncio e público, na circulação e no consumo do conteúdo publicitário pelo leitor. Não obstante, é prudente esclarecer que esse leitor não é totalmente livre em seu processo de leitura, pois está cercado pela historicidade e determinado por um modo de ler que Ihe retira o papel hegemônico da criatividade no ato interpretativo. Isso se deve à formação discursiva a que se filia o sujeitoleitor, determinando o efeito de sentido para a materialidade discursiva.

\section{O jogo entre paráfrase e polissemia no fazer publicitário}

Serrani (1993) também examina a noção de paráfrase, colocando-a em uma nova perspectiva, a fim de elucidar e enriquecer o pensar acerca desse tema. A autora introduz e explica a noção de ressonância de significação: "entendo que 
há paráfrase quando podemos estabelecer entre as unidades envolvidas uma ressonância - interdiscursiva - de significação, que tende a construir a realidade (imaginária) de um sentido" (p. 47).

Nessa explicitação do que vem a ser a ressonância de significação, Serrani revela que as paráfrases ressoam significativamente na verticalidade do discurso e se concretizam na horizontalidade. A noção de ressonância de significação se aplica ao processo de criação do discurso publicitário e à discussão sobre produtividade e criatividade. Já atestamos que as paráfrases ressoam em todos os momentos do percurso gerativo da ideia, o que representaria para Serrani a verticalidade do discurso; e se concretizam no anúncio publicitário (o intradiscurso), a horizontalidade apontada pela autora, reafirmando que o anúncio é uma paráfrase do briefing e dos demais momentos do processo.

Serrani (1993) aprofunda o tema, propondo as ressonâncias de significação em torno de modos de dizer. Esse tipo de ressonância refere-se aos efeitos de sentido produzidos pela repetição em nível interdiscursivo, que repercutem na estruturação do discurso. Os sentidos se espalham na horizontalização, sem deixar, contudo, de ecoar, fazendo ressoar um modo específico de dizer.

A SD10, colhida durante o brainstorm, demonstra que a figura do pássaro foi o modo escolhido pelos criativos para dizer aquilo que o anunciante pretendia (SDs 4 e 5), ressoando um significado específico. Foi o modo de dizer - diferente e indireto - encontrado para ressoar o mesmo efeito de sentido.

SD10 - em geral o pássaro é um símbolo de liberdade, de voar, de não ter fronteiras, de não ter limites.

SD4 - expandir, atravessar fronteiras, ultrapassar, aumentar, chegar.

SD5 - falar em crescimento, já que resultados mostram que o cliente está expandindo.

A SD11 contribui para evidenciar que as ideias criativas podem não se repetir, porém o efeito de sentido se repete, redundando em formulação diferente 
no interior do mesmo. A despeito da tentativa de fazer com que o sentido não se repita (ele sempre outro), ressoa o mesmo sentido, independente do modo de dizer. Foi o que verificamos nas SDs 6, 7 e 8. Os sentidos foram parafraseados, isto é, acrescentando ou tirando alguns detalhes até ressoarem no nascimento de formulações que retornam ao mesmo espaço do dizer.

SD11 - em cima de uma ideia a gente consegue ter outra ideia e também é importante pra gente não repetir ideia.

SD6 - fases de crescimento com tênis menor e dedo para fora furado.

SD7 - conforme vai escrevendo a fonte vai crescendo. Há espaço para crescer. Está crescendo tanto que teve que ir para outro estado também.

SD8 - o texto estourado, encostado nas bordas ou até cortando um pouco as letras, para dizer que o cliente está expandindo.

A noção de ressonância de significação nos permite caracterizar a ressonância de modos de dizer entre as três ideias criativas (SDs 6, 7 e 8). Outras vozes vindas do interdiscurso ressoam na criação do discurso publicitário, uma vez que, conforme adiantou Serrani (1993), a paráfrase é do nível do interdiscurso, e a ressonância, por atacado, também. Esse conjunto de três SDs avaliza que um mesmo sentido ressoa na horizontalização.

Nesse ínterim, destacamos que é natural que ocorram deslizamentos de sentido no processo de produção de ideias, antes de se encerrar e redundar no anúncio e de chegar ao seu destino. Aproximando-nos da noção de deslizamento da $A D$, é Pêcheux (2002) quem aponta para a transformação dos sentidos e, de acordo com o autor, "todo enunciado é intrinsecamente suscetível de tornar-se outro diferente de si mesmo" (p. 53). Uma ideia criada durante o processo é fruto de outras ideias, assim como pode acarretar novas ideias. Em outros termos, no transcorrer do fluxo das ideias no processo criativo acontece o deslizamento dos sentidos, deslocando-se o sentido de uma ideia criativa para outro sentido e, possivelmente, para derivar uma nova ideia criativa, em uma fase de testes 
e experimentações. É em função dos deslizamentos de sentido que pode haver transferências ou derivações, abrindo espaço para uma constelação de ideias, desde que retomem um mesmo dizer. Mas antes disso, na fase de elaboração daquilo que será dito publicitariamente, os profissionais de criação estão interpretando, portanto produzindo sentidos, em uma corrente entre produção e interpretação.

A prova de que há deslizamentos de sentido no processo de produção do conteúdo publicitário, mas que ao seu pretenso desfecho as ideias criativas precisam (re)produzir um mesmo efeito de sentido, está nas SDs 12 e 13, tomadas do brainstorm, em um diálogo entre a dupla de criação. O diretor de arte expõe ao redator uma ideia (SD12), porém é avisado pelo redator que o referente (caminhão de mudança) escolhido para representar a ideia causaria um deslizamento de sentido (SD13). A ideia foi descartada porque não resultaria em uma peça publicitária dotada de um efeito de homogeneidade. Assim, toda peça publicitária é, simultaneamente, produto de deslizamento de sentido - na medida em que no brainstorm proliferam inúmeras ideias, embora somente perpetuem aquelas que (re)produzem um mesmo efeito de sentido - e matéria-prima para deslizamento de sentido. No brainstorm, os deslizamentos ocorrem para permitir a diversidade do mesmo, isto é, para possibilitar a descoberta das diferentes maneiras de dizer o mesmo. Nesse contexto, o sujeito criativo é encarregado de organizar a multiplicidade de sentidos e conservar o sentido dominante. Dito de outra forma, no processo de construção do discurso publicitário, a paráfrase decorre da polissemia.

SD12 - caminhão de mudança, o motorista com viseira, protetor solar e óculos de sol, como se estivesse indo para a praia.

SD13 - cuidado para não dizer que está saindo daqui, pois não está. Está chegando.

De imediato, acrescentamos que a partir deste estudo encaramos a liberdade criativa como um efeito do imaginário. Entendemos que o poder da 
criatividade se centra na capacidade de mobilizar o discurso-outro e de (re) formulá-lo, (res)significá-lo. Se a criatividade estiver relacionada a (re)inventar, a (re)produzir, a (res)soar o mesmo sentido, embora de modo diferente, ela é da ordem da produtividade, logo, da paráfrase. Pressupomos, assim, que na publicidade nada é autêntico ou original. Há, sim, um efeito de criatividade (efeito de novidade), amparado no mascaramento do discurso-outro para intensificar a impressão de homogeneidade. Mesmo diante de tal constatação, lembramos que o processo de construção do discurso publicitário não é um espaço discursivo de pura reprodução de sentidos, pois se houver reformulações, é porque há deslizamentos de sentido, conforme mostramos com a SD14:

SD14 - acaba sendo mais tranquilo de vir a próxima ideia porque já tem a segurança de já ter tido umas duas ou três antes.

Embora as primeiras ideias não respeitem o sentido pré-construído no briefing - configurando o seu abandono pontual e provisório - servem para "soltar" o criativo. Posteriormente elas serão descartadas, mas redundarão em ideias com o sentido pretendido, ou seja, serão reorganizadas, tendo cumprido a tarefa de ponto de partida para novas ideias. Equivale a dizer que, a partir das ideias iniciais, os sentidos deslizam para, em seguida, retornarem à diversidade em torno do mesmo. Caso não houvesse esse regresso ao efeito de sentido dominante, as primeiras ideias nem serventia teriam, correndo o risco de nem serem aproveitadas para retomadas. Haja vista que os limites entre o mesmo e o diferente são bastante tênues, são nas sutilezas do jogo e nas armadilhas do funcionamento discursivo que fundamentamos a sentença: parece criativo, mas é paráfrase. A criatividade "deixa voar, mas determina os procedimentos de descida. Em solo, obriga a passagem pela alfândega, é crítica e rigorosa, descarta ideias frágeis ou apenas belas e sem utilidade, pede mudanças" (CAPOTE FILHO, 2014, p. 130).

A partir disso, retomamos a noção de processo criativo para (res) significá-lo como processo de produção, pois não dá origem, mas sim forma 
as ideias que são retomadas, reformulando-as. O processo de produção é um (re)dizer, porém de modo a provocar um efeito de sentido diverso. Equivale a declarar que no processo de produção se "diz de novo", e não se "diz o novo". Dito de outro modo, desenvolve-se o "já-lá" para (re)dizê-lo "aquiagora". Propomos conceber esse mesmo processo como um acontecimento enunciativo que produz um efeito de sentido entre interlocutores, materializa o sujeito inconsciente e ideológico pela língua e ainda manifesta o caráter heterogêneo do próprio processo, bem como do sujeito.

Reafirmando nossa posição, sustentados na Análise de Discurso, de ressignificar o processo criativo do discurso publicitário, estabelece-se mais um efeito: o efeito de processo criativo, decorrente do efeito de criatividade. $\mathrm{Na}$ realidade, o processo é de produção, em que, pela produtividade, se faz parecer novo e original aquilo que se está repetindo. Em uma linguagem mais próxima à $A D$, diríamos que no processo produtivo se renovam e se materializam ideias "criativas", o que já é da ordem do repetido.

\section{Considerações finais}

No cenário construído até aqui, o processo de produção das ideias publicitárias se constitui como um espaço de representação da heterogeneidade. Dada a sua relação com a exterioridade, passamos a compreendê-lo como o lugar de reprodução de pré-construídos e o momento em que se criam as condições para os publicitários reproduzirem dizeres, e não propriamente um lugar de criatividade.

Mesmo diante do atravessamento de vozes e discursos, os profissionais de criação carregam a ilusão de ser a fonte do dizer. Tal afetação é reforçada no juízo de que estão, efetivamente, criando, quando na aplicação da técnica do brainstorm, eles próprios participam dos movimentos do jogo publicitário: primeiro permitir para depois evitar o deslizamento de sentido, e, assim, estar refém do briefing, da paráfrase e, por extensão, da produtividade. Os criativos até transitam pela polissemia, relevando dessa maneira que sempre é possível 
deslizar ao assujeitamento, pois como lembra Pêcheux (1997) "apreender até seu limite máximo a interpelação ideológica como ritual supõe reconhecer que não há ritual sem falhas" (p. 300); mas retornam à paráfrase. Em síntese, no processo de criação publicitária, parte-se de uma paráfrase (o briefing, materialização do discurso do anunciante traduzido para os profissionais de criação) para gerar a polissemia (no brainstorm há deslizamento de sentido) e retorna-se à paráfrase (a peça publicitária, materialização do briefing) para gerar novamente a polissemia (na interação entre leitor e conteúdo publicitário).

Nesse instante é que se configura a divisão do sujeito criativo. Seu desejo de criatividade, por meio da polissemia, é sufocado, e ele se depara com a perspectiva de produtividade. Nessa circunstância, diante das condições de produção, o criativo fica subordinado à dominância de um sentido, (sobre) vivendo sob o efeito de liberdade criativa. Do mesmo modo, o processo de constituição do discurso publicitário também oscila, vacila e se move. Ele tende à paráfrase, por mais que enverede pela polissemia na constante movimentação de sentido durante o brainstorm. Paráfrase e polissemia se imbricam o tempo inteiro, mas o que se sobressai é a produtividade, porque a paráfrase subsiste, levando-se em conta que sempre há o retorno ao mesmo espaço do dizer.

Esse é o jogo do processo de criação do discurso publicitário (HANSEN, 2013). Por um lado, para o consumo externo à agência, o sujeito criativo ocupa o lugar da criação livre e pura, venerando o brainstorm pela sensação de independência em relação ao sentido dominante, e demonizando o briefing, por representar justamente o contrário - a submissão ao sentido dominante. Por outro lado, interno à agência, o lugar do criativo é de reprodução, de serialização de saberes, lugar permeado por confrontos entre posições-sujeito e regulado por relações de desigualdade, contradição, além da subordinação e assujeitamento à ideologia do anunciante. 


\section{Referências}

ALVES, M. C. D. A invenção do criativo publicitário: identidade e discurso. In: XXXV CONGRESSO BRASILEIRO DE CIÊNCIAS DA COMUNICAÇÃO, 2012. Anais...

Disponível em <http://www.intercom.org.br/sis/2012/resumos/R7-0560-1. pdf>. Acesso em 26 de outubro de 2015.

BARRETO, R. M. A criatividade no trabalho e na vida. São Paulo: Summus, 1997.

BURROWES, P. Viagem ao território da publicidade. Comunicação, Mídia e Consumo, v. 2, n. 5, p. 205-219, nov. 2005.

CAPOTE FILHO, H. S. Criatividade: o avesso do avesso, do avesso, do avesso. In: NICOLA, R. M. S. Ensaios sobre docência universitária. Curitiba: PUCPRess, 2014.

CARRASCOZA, J. A. Do caos à criação publicitária. São Paulo: Saraiva, 2008.

DIEGUEZ, G. K. O discurso publicitário: desvendando a sedução. Comum, v. 12, n. 27, p. 86-106, jul./dez. 2006.

FOSTER, J. Como ter novas ideias. São Paulo: Futura, 1997.

HANSEN, F. (In)verdades sobre os profissionais de criação: poder, desejo, imaginação e autoria. Porto Alegre: Entremeios, 2013.

MARTINS, J. S. Redação publicitária: teoria e prática. São Paulo: Atlas, 1997.

ORLANDI, E. A linguagem e seu funcionamento. Campinas: Pontes, 1987. Análise de discurso: princípios e procedimentos. 3. ed. Campinas: Pontes, 2001. 
PÊCHEUX, M. Análise automática do discurso. In: GADET, F.; HAK, T. (Orgs.). Por uma análise automática do discurso. 2 ed. Campinas: Unicamp, 1993, p. 61-161.

. Semântica e discurso: uma crítica à afirmação do óbvio. 3. ed. Campinas: Unicamp, 1997.

O Discurso: estrutura ou acontecimento. 3. ed. Campinas: Pontes, 2002.

PINHEIRO, C. M. P.; MARTINS, F. E. M.; BARTH, M. Economia criativa: questões sobre o processo criativo. Animus, v. 13, p. 1-15, 2014.

PREDEBON, J. Criatividade: abrindo o lado inovador da mente. São Paulo: Atlas, 1997.

SERRANI, S. M. A linguagem na pesquisa sociocultural: um estudo da repetição na discursividade. Campinas: Unicamp, 1993.

submetido em: 03 fev. 2015 | aprovado em: 15 mai. 2015 